\title{
Thermodynamic and mechanical characterisation of kaolin clay
}

\author{
I. Hammouda, D. Mihoubi* \\ Research and Technology Center of Energy, Thermal Processing Laboratory, B.P. 95, 2050, Hammam-Lif, Tunisia \\ "Corresponding author: e-mail: daoued.mihoubi@crten.rnrt.tn
}

\begin{abstract}
This study deals with experimental thermodynamic and rheological characterization of kaolin. Water sorption isotherms of kaolin were determined for three temperatures $\left(30,50\right.$ and $\left.70^{\circ} \mathrm{C}\right)$. Desorption isotherms were fitted by using five models (GAB, BET, Henderson modified, Adam and Shove, Peleg) among the most used ones in literature. The GAB model was found to be the most suitable for describing the relationship between equilibrium moisture content and water activity for the whole range of temperature $\left(30-70^{\circ} \mathrm{C}\right)$ and relative humidity $(0-100 \%)$. Desorption enthalpy and entropy were determined. The desorption enthalpy decreases with increasing moisture content. The density and the shrinkage of the material and the Young's modulus variations as a function of moisture content were determined experimentally. The Young modulus varies between $0.1 \mathrm{MPa}$ and $14 \mathrm{MPa}$. The viscoelastic parameters of kaolin were also determined by using a series of Prony.
\end{abstract}

Keywords: drying, desorption isotherms, volume shrinkage, Young's modulus, relaxation.

\section{INTRODUCTION}

The basic process of drying is a necessary step in many industries sectors. Drying has to be performed for several types of deformable materials such as clays. The kaolin is frequently used as a model for the mathematical modelling of the drying process of deformable media because it is available, simple to manipulate and it is homogeneous and isotropic media. During the drying of such porous media, three types of transport can coexist: mass, heat and momentum transports accompanied by physical changes in the product. The kinetics of drying depends on the thermodynamic and physical properties of the product. Therefore the knowledge of thermodynamic and rheological properties of the product is an essential step in design and optimization of a drying process.

The moisture sorption isotherms express the hygroscopic equilibrium states of a given product. Their determination constitutes an important stage for better understanding of the product behaviour related to the modelling of drying processes ${ }^{1}$. In fact, using a suitable model for the analysis of experimental data is a key to the good assessment of the drying process.

The rheological, physicochemical and quality indicators of the product could be changed during drying. The identification of the variation of mechanical properties of deformable media during dehydration is essential for further modelling investigation. For example, the Young's modulus is often taken as constant parameter in the models dealing with drying ${ }^{2,3}$. Moreover, in the majority of drying models including shrinkage effects, the mechanical behaviour of materials is generally characterised by elastic behaviours ${ }^{4-6}$. Many authors ${ }^{7-14}$ found that most products cannot really fit into this simple model and propose complex models which take into account the variation of many parameters (young modulus, diffusion coefficient, density,...) with moisture content, temperature and drying time.

The present study deals with experimental characterisation of kaolin during convective drying. The essential characteristics of the clay product were investigated. The desorption isotherms of kaolin were determined at 30,50 , and $70^{\circ} \mathrm{C}$. Several models were used to fit the experimental results. Enthalpy and entropy of desorption were deduced from desorption isotherms data.
The relation between the product density and moisture content is determined and the shrinkage is evaluated. The Young's modulus variation of kaolin as function of moisture content was calculated and the relaxation function of kaolin was identified in order to suggest a generalised Maxwell model describing the viscoelastic behaviour of the clay.

\section{MATERIALS AND METHODS}

\section{Product identification}

The kaolin used in this study is a commercial clay (K7375 Sigma Aldrich ${ }^{\circledR}$, France). The mineral characterization of kaolin was made by using Analytical diffractometer (X'PERT Pro PAN) with Cu Ka radiation $\mathrm{k}=1.5418 \AA$

\section{Sorption isotherms}

The desorption isotherms were determined using the standard gravimetric method, in which the weight was monitored discontinuously within a standard static system of thermally stabilized desiccators. This method was recommended by the COST 90 project ${ }^{15}$. The samples are previously saturated with water. The samples of the material under investigation are placed inside a desiccator of specified relative humidity. A range of a relative humidity varying from 0.6 to $98.1 \%$ was provided by using a sulphuric acid solutions ${ }^{16}$. The desiccators were kept in temperature controlled cabinets at constant temperatures of 30,50 and $70^{\circ} \mathrm{C}$. The samples reach equilibrium after one or two weeks. The equilibrium was considered reached, when a constant weight is obtained $( \pm 0.001$ g). The dry mass was determined by drying samples in a conventional oven at $105^{\circ} \mathrm{C}$ for $24 \mathrm{~h}$.

\section{Product density}

The relation between the apparent density of the product and its moisture content was investigated by means of an apparatus based on Archimedes's law. The volume of the sample is determined by measuring the difference in weight of that sample above and under water. The sample is coated with paraffin to prevent the uptake of water. 
The variation of specific volume reduced to the unit of dry mass $\left(\mathrm{m}^{3} / \mathrm{kg}\right)$ with the moisture content, according to others works ${ }^{5,17-19}$ is plotted in Figure 1. Linear variation for high moisture content and a constant value for low moisture content:

$$
\begin{aligned}
& \mathrm{w} \geq \mathrm{w}_{\mathrm{r}}: \overline{\mathrm{V}}=\overline{\mathrm{V}}_{\mathrm{s}}\left(1+\varepsilon\left(\mathrm{w}-\mathrm{w}_{\mathrm{r}}\right)\right) \\
& \mathrm{w} \leqslant \mathrm{w}_{\mathrm{r}}: \overline{\mathrm{V}}=\overline{\mathrm{V}}_{\mathrm{s}}
\end{aligned}
$$

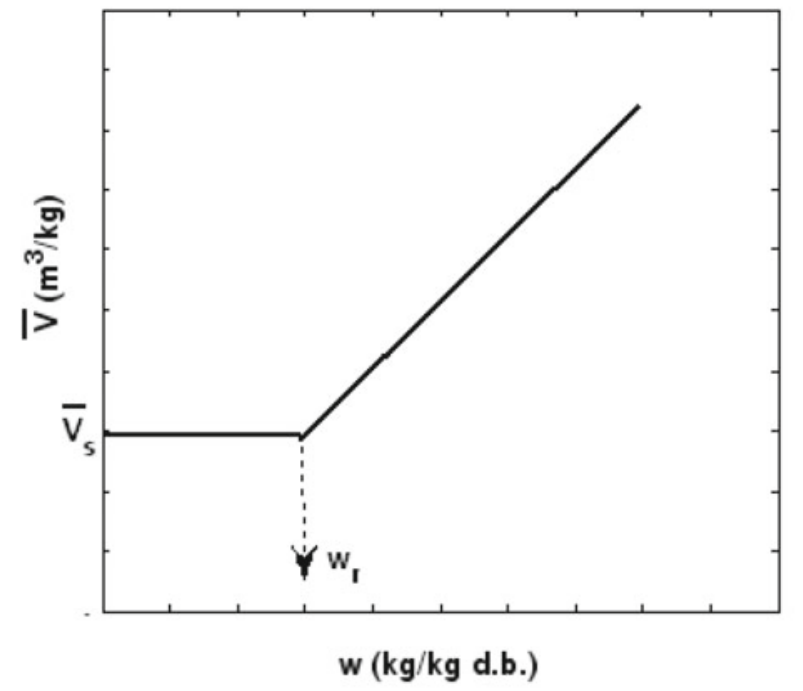

Figure 1. Typical shrinkage curve

where $\varepsilon$ is the shrinkage coefficient, $\bar{\nabla}$ the specific volume at material moisture content $\mathrm{w}, \overline{\mathrm{V}}_{\mathrm{s}}$ the specific volume of material at moisture content $\mathrm{w}=0, \rho$ is the apparent density of the material and $\rho_{\mathrm{s}}$ is the apparent density of the solid phase defined as

Thus:

$\mathrm{W} \geq \mathrm{W}_{\mathrm{r}}: \rho=\frac{1}{\overline{\mathrm{V}}_{\mathrm{s}}}\left(\frac{1+\mathrm{w}}{1+\varepsilon\left(\mathrm{w}-\mathrm{w}_{\mathrm{r}}\right)}\right)$

$\mathrm{W} \leqslant \mathrm{W}_{\mathrm{r}}: \rho=\frac{1}{\nabla_{s}}(1+w)=\rho_{s}(1+w)$

\section{Young's modulus determination}

Experimental studies dealing with the mechanical characterisation of kaolin have focused mainly on the determination of the Young's modulus and its variation with moisture content. Uniaxial compression tests were undertaken on kaolin clay having different moisture content by using a traction/compression machine (LRX Plus, Lloyd Instruments). Tests were applied on cylindrical samples (diameter $=$ height $=0.01 \mathrm{~m}$ ) with a small displacement rate of $0.1 \mathrm{~mm} / \mathrm{mn}$ in order to avoid a brutal rupture of the samples. The Young's modulus is defined as

$E=\frac{\sigma}{\varepsilon}$ were $\sigma$ is the uniaxial compression stress and $\varepsilon$ is the strain.

\section{Relaxation function determination}

The determination of the relaxation function is essential to study the viscoelastic behaviour of kaolin clay. The relaxation test (Fig. 2) is performed by imposing suddenly a deformation, and then it is kept constant over time. The resulting stress gradually decreases over time. The stress drops while the viscoelastic deformation remains constant.

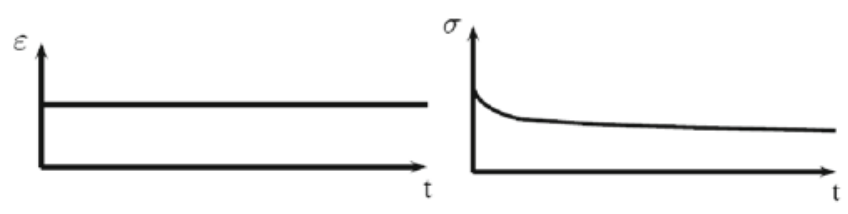

Figure 2. Variation of deformation $(\varepsilon)$ and stress $(\sigma)$ with time during relaxation test

The test was undertaken on a cylinder of kaolin $($ diameter $=$ height $=15 \mathrm{~mm})$. The test performed for the determination of the relaxation function consists on applying a compression (strain rate $0.9 \%$ to stay in the field of linear viscoelasticity) and controlling the evolution of the resulted stress. The test is stopped when the stress value is kept constant.

\section{EXPERIMENTAL RESULTS}

\section{Mineral characterisation of kaolin}

Figure 3 show the X-ray diffraction pattern of kaolin clay. It mark the presence of an intense peak characteristic of kaolinite $(001)=7.16 \AA$ and the presence of a quantity of illite $(10 \AA)$. Fractions of quartz, feldsparth and dolomite are also detected.

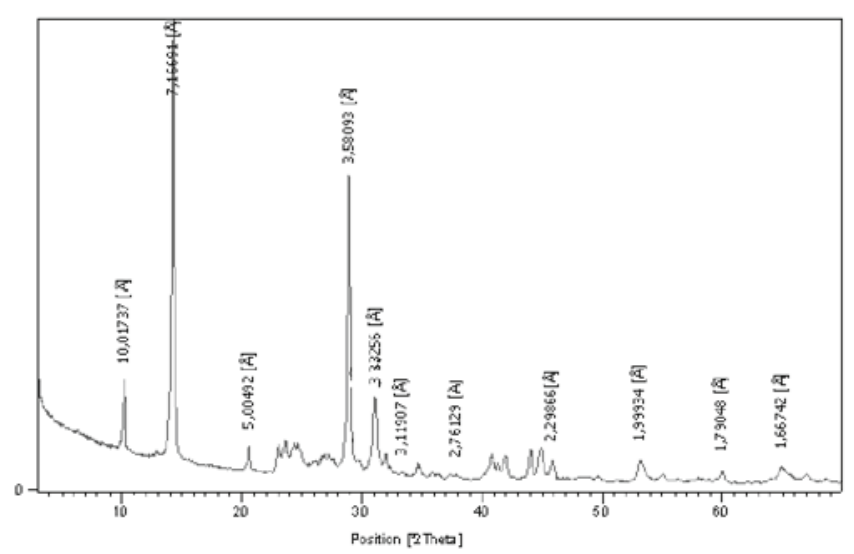

Figure 3. X-ray diffraction pattern of a kaolin powder

The X-ray diffraction pattern of an oriented blade of kaolin $(\mathrm{KN})$ observed in figure 4 confirms the existence of a significant fraction of kaolinite, equidistance $7.13 \AA$ in the (001) plane, which was unaltered in the presence of ethylene glycol $(\mathrm{KG})$ and disappears after heating at $500^{\circ} \mathrm{C}(\mathrm{KC})$. Illite peak is also observed $(10 \AA)$ and whose equidistance remains unchanged in all three cases.

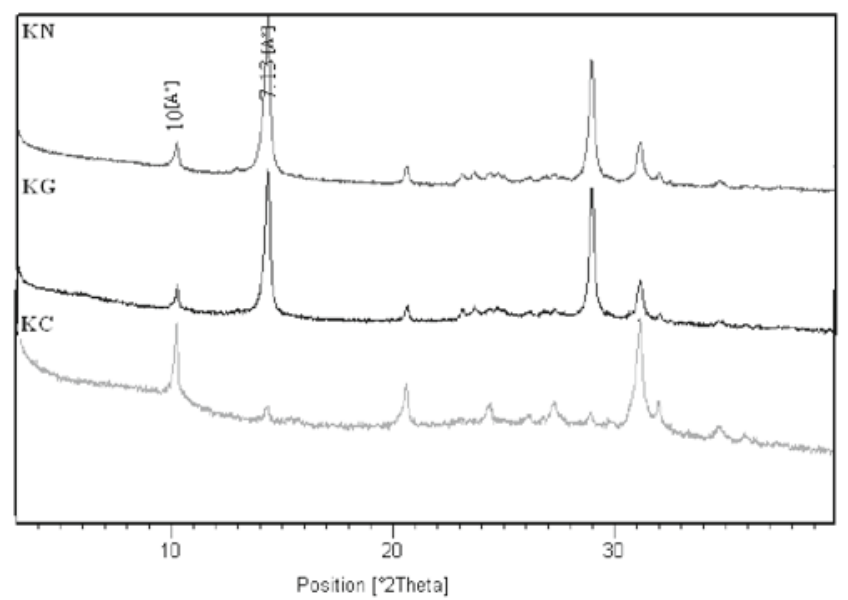

Figure 4. X-ray diffraction patterns of kaolin (oriented blade analysis) 


\section{Sorption isotherms}

Desorption isotherms of kaolin at three temperatures $\left(30,50,70^{\circ} \mathrm{C}\right)$ are presented in Figure 5. The figure shows a sigmoid shape. The equilibrium moisture content decreases with the increasing of temperature. This behaviour is typical of many products such as plants, foods and clay materials. The power desorption of kaolin is low by comparison with other types of clays such as bentonite ${ }^{5,20-22}$. The reached equilibrium moisture content is $0.06 \mathrm{~kg} / \mathrm{kg}$ d.b at $30^{\circ} \mathrm{C}$ when it reached $0.4 \mathrm{~kg} / \mathrm{kg}$ d.b. for bentonite at the same temperature ${ }^{20}$.

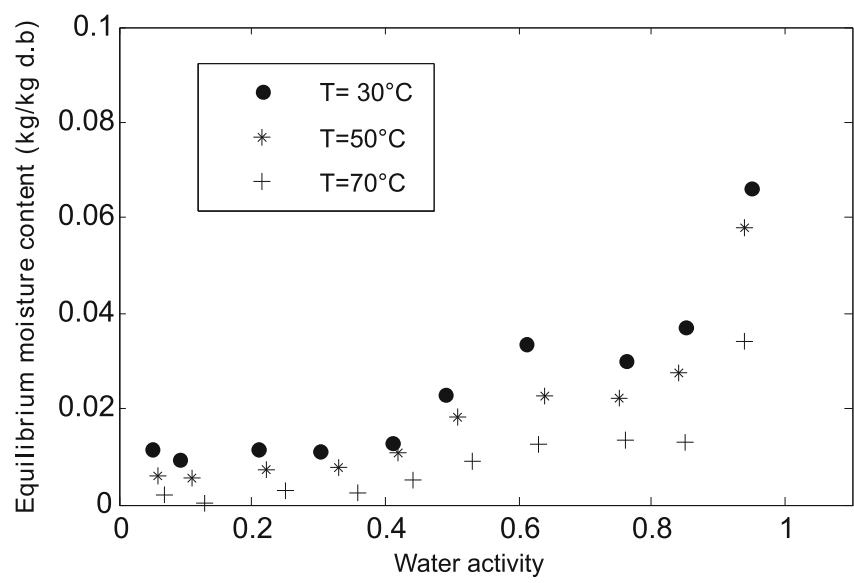

Figure 5. Experimental desorption isotherms of kaolin at 30, 50 and $70^{\circ} \mathrm{C}$

\section{Modelling}

Many models have been reported in literature to mathematically express the relation between the water activity and the equilibrium moisture content of a product. These models can be theoretical ${ }^{23-27}$, semi-theoretical ${ }^{28,29}$ or empirical ${ }^{30,31}$. The choice of an appropriate model depends on a number of factors such as the area under study $^{32}$.

The models that are used to describe the sorption behaviour of kaolin clay are summarised in Table 1 .

For regression curve fits, error is assessed using the standard error $\mathrm{S}$ and correlation coefficient $\mathrm{R}$. The standard error of the estimate is defined as follows:

$$
S=\sqrt{\frac{\sum_{i=1}^{N}\left(w_{e q_{i, e x p}}-w_{e q_{i, p r e}}\right)^{2}}{d_{f}}}
$$

Where $\mathrm{w}_{\text {eqi,exp }}$ is the $\mathrm{i}^{\text {th }}$ experimental value of equilibrium moisture content. And $\mathrm{w}_{\text {eqi,pre }}$ is the $\mathrm{i}^{\text {th }}$ value of moisture content calculated from the regression model. $\mathrm{N}$ is the number of experimental points and $\mathrm{d}_{\mathrm{f}}$ is the number of degree of freedom defined as the difference between the number of experimental points and the number of parameters in the particular model.

Another measure of the "goodness of fit" is the correlation coefficient expressed as

$$
R=\sqrt{\frac{\sum_{i=1}^{N}\left(w_{e q_{i, p r e}}-w_{m, \exp }\right)^{2}}{\sum_{i=1}^{N}\left(w_{\text {eq }} q_{i, \exp }-w_{m, \exp }\right)^{2}}}
$$

Where $\mathrm{w}_{\mathrm{m} \text {,exp }}$ is the experimental mean moisture content defined as

$$
\mathrm{w}_{\mathrm{m}, \exp }=\frac{1}{\mathrm{~N}} \sum_{\mathrm{i}=1}^{\mathrm{N}} \mathrm{w}_{\mathrm{eq}} \mathrm{q}_{\mathrm{i}, \exp }
$$

The value of models parameters and the corresponding statistical parameters obtained for the fitting kaolin desorption isotherms are presented in Table 2. They show that the models of GAB and modified Henderson are well suited to kaolin, with a relative error between the theoretical and experimental values, respectively, lower than $6 \%$ and $3.5 \%$. The results of BET, Henderson modified, Adam and Shove and Peleg Models of are not satisfactory (relative error close to $40 \%$ ).

The GAB is the best model for fitting kaolin sorption isotherms with a correlation coefficient close to the unit and standard error values relatively low. This result is in concordance with other works ${ }^{20,21}$ which deal with clay. A comparison between the GAB model and the experimental sorption data are shown in Figure 6.

Isosteric heat of desorption and desorption entropy

The operation of drying is accompanied by the heat required to remove water from the material. The heat of desorption is defined as the increase in enthalpy when 1 mole of a substance is desorbed from another at a constant pressure.

The net isosteric heat of desorption or enthalpy of desorption $\left(\Delta \mathrm{H}_{\mathrm{s}}\right)$ is defined as the difference between the total isosteric heat of desorption and the latent heat of pure water. It can be determined from moisture desorption data using the following equation which is derived from the Clausius-Clapeyron equation ${ }^{38}$ :

$$
\left(\frac{\partial\left(\ln \mathrm{a}_{\mathrm{w}}\right)}{\partial\left(\frac{1}{\mathrm{~T}}\right)}\right)_{\mathrm{w}}=-\frac{\Delta \mathrm{H}_{\mathrm{S}}}{\mathrm{R}}
$$

\begin{tabular}{|c|c|c|}
\hline Model & Equation & Parameters \\
\hline Guggenhein, Anderson and De Boer (GAB) $)^{33}$ & 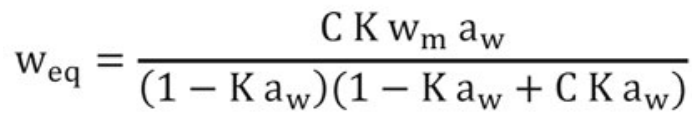 & $\mathrm{C}, \mathrm{K}, \mathrm{w}_{\mathrm{m}}$ \\
\hline Brunauer, Emmet et Teller (BET) $)^{34}$ & $\mathrm{w}_{\mathrm{eq}}=\frac{\mathrm{w}_{\mathrm{m}} \mathrm{C}}{\left(1-\mathrm{a}_{\mathrm{w}}\right)\left(1+(\mathrm{C}-1) \mathrm{a}_{\mathrm{w}}\right)}$ & $\mathrm{C}, \mathrm{w}_{\mathrm{m}}$ \\
\hline modified Henderson ${ }^{35}$ & $\mathrm{w}_{\mathrm{eq}}=\left(\frac{\ln \left(1-\mathrm{a}_{\mathrm{w}}\right)}{-\mathrm{A}(\mathrm{T}+\mathrm{B})}\right)^{1 / \mathrm{c}}$ & A, B, C \\
\hline Adam et Shove $^{36}$ & $\mathrm{w}_{\mathrm{eq}}=\mathrm{A}+\mathrm{B} \mathrm{a}_{\mathrm{w}}+\mathrm{Ca}_{w}^{2}+\mathrm{D} \mathrm{a}_{w}^{3}$ & $A, B, C, D$ \\
\hline Peleg ${ }^{37}$ & $\mathrm{w}_{\mathrm{eq}}=\mathrm{Aa} \mathrm{a}_{w}^{B}+\mathrm{C} \mathrm{a}_{w}^{D}$ & $A, B, C, D$ \\
\hline
\end{tabular}

Table 1. Mathematical expressions of the models used for desorption isotherms 
Table 2. Models and statistical parameters obtained for the desorption isotherms of kaolin at 30,50 and $70^{\circ} \mathrm{C}$

\begin{tabular}{|c|c|c|c|c|}
\hline \multirow[t]{2}{*}{ Model } & \multirow[t]{2}{*}{ Model parameters } & \multicolumn{3}{|c|}{ Temperature $\left({ }^{\circ} \mathrm{C}\right)$} \\
\hline & & 30 & 50 & 70 \\
\hline & $\mathrm{K}$ & 0.876 & 0.929 & 0.954 \\
\hline & C & 160.3 & 41.19 & 9.212 \\
\hline \multirow[t]{4}{*}{ GAB } & Wm & 0.0108 & 0.0071 & 0.0034 \\
\hline & $\mathrm{R}^{2}$ & 0.9321 & 0.9506 & 0.9324 \\
\hline & $\mathrm{s}$ & 0.00531 & 0.00354 & 0.00293 \\
\hline & $C$ & 4277 & 2486 & 95.84 \\
\hline \multirow[t]{5}{*}{ BET } & $\mathrm{w}_{\mathrm{m}}$ & 0.003971 & 0.003903 & 0.002174 \\
\hline & $\mathrm{R}^{2}$ & 0.5005 & 0.8095 & 0.878 \\
\hline & $\mathrm{S}$ & 0.01348 & 0.00697 & 0.003478 \\
\hline & A & 0.5123 & 0.1873 & 0.151 \\
\hline & B & 0.7855 & 0.4689 & 0.6884 \\
\hline \multirow[t]{5}{*}{ Modified Henderson } & $C$ & 1.412 & 1.046 & 0.8415 \\
\hline & $\mathrm{R}^{2}$ & 0.8767 & 0.9096 & 0.8941 \\
\hline & $\mathrm{S}$ & 0.006315 & 0.0048 & 0.0032 \\
\hline & $\mathrm{A}$ & 0.007421 & -0.000141 & -0.0025 \\
\hline & B & 0.03932 & 0.0784 & 0.04674 \\
\hline \multirow[t]{6}{*}{ Adam and Shove } & C & -0.08693 & -0.1987 & -0.113 \\
\hline & $\mathrm{D}$ & 0.11 & 0.1864 & 0.106 \\
\hline & $\mathrm{R}^{2}$ & 0.8575 & 0.8796 & 0.8106 \\
\hline & $\mathrm{S}$ & 0.006789 & 0.005543 & 0.004334 \\
\hline & A & 0.08144 & -0.001079 & 0.02216 \\
\hline & B & 19.33 & 0.89 & 2.446 \\
\hline \multirow[t]{4}{*}{ Peleg } & C & 0.03747 & 0.04254 & 0.009696 \\
\hline & $\mathrm{D}$ & 0.7041 & 1.084 & 2.541 \\
\hline & $\mathrm{R}^{2}$ & 0.9053 & 0.6372 & 0.7633 \\
\hline & $\mathrm{s}$ & 0.005534 & 0.00962 & 0.004845 \\
\hline
\end{tabular}

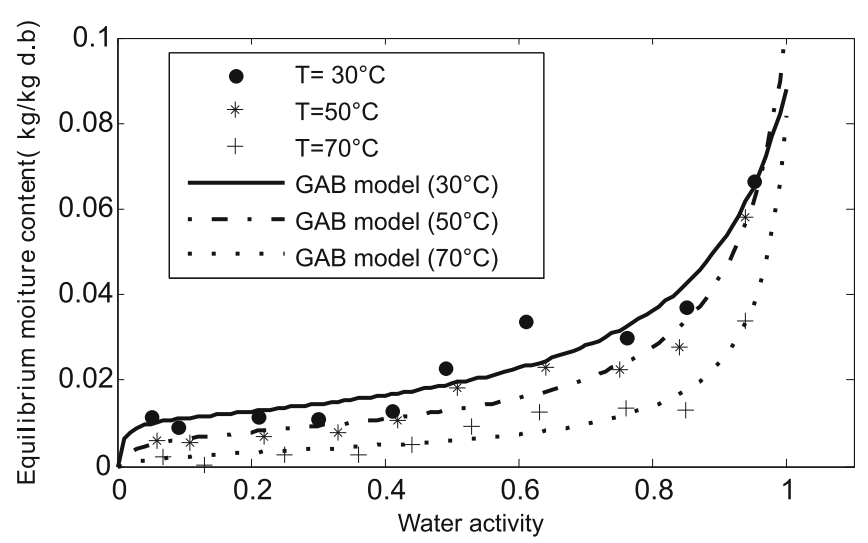

Figure 6. Comparison between the GAB model and the experimental desorption data at 30,50 and $70^{\circ} \mathrm{C}$

$\Delta \mathrm{H}_{\mathrm{s}}$ is the isosteric enthalpy of desorption which can be evaluated from the slope of the curve of $\left(1 / \mathrm{T} ; \ln \mathrm{a}_{\mathrm{w}}\right)$ for fixed values of moisture content .

The values of determined desorption enthalpy are presented in Figure 7. The isosteric heats of desorption have a strong dependence on moisture content, with an increase of the energy required for desorption (in excess of the latent heat) at low equilibrium moisture contents. For little values of moisture content, the water is strongly bound to the material. For this reason, the corresponding desorption enthalpy is very high, it was $10^{5} \mathrm{~J} / \mathrm{mol}$ at moisture content of $0.01 \mathrm{~kg} / \mathrm{kg}$ d.b. Whereas, for higher moisture content the energy required for water evaporation is very low because the product contains a lot of free water easy to remove. An almost constant energy input of $3126 \mathrm{~J} / \mathrm{mol}$ is needed to desorb moisture from kaolin clay above moisture content of $0.04 \mathrm{~kg} / \mathrm{kg}$ d.b. The experimental values of the isosteric heat obtained in this work follow the trend of curves found by other authors in clay and food material ${ }^{20,21,39}$.

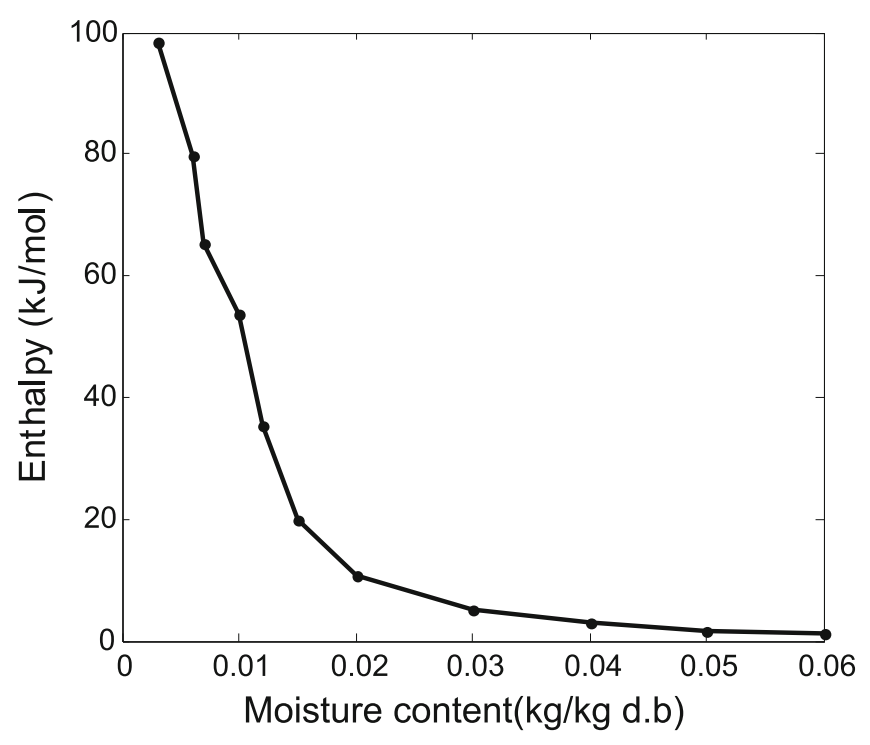

Figure 7. Variation of desorption enthalpy with moisture content of kaolin

\section{Desorption entropy}

Entropy at any temperature is equivalent to the lost work and gives a measure of the energy that is not available to perform work. Entropy may be associated with the binding, or repulsive, forces in the system and is associated with the spatial arrangements at the watersorbent interface. Thus, entropy characterises, or defines the degree of order or randomness existing in the watersorbent system and helps interpretation of processes such as dissolution, crystallization and swelling ${ }^{\mathbf{4 0}}$.

The desorption entropy is deduced from the sorption entropy using the following relation:

$\ln \left(\mathrm{a}_{\mathrm{w}}\right)=\frac{\Delta \mathrm{H}_{\mathrm{S}}}{\mathrm{RT}}-\frac{\Delta \mathrm{S}}{\mathrm{R}}$

Figure 8 shows the desorption entropy as a function of moisture content. The results showed the strong depend- 


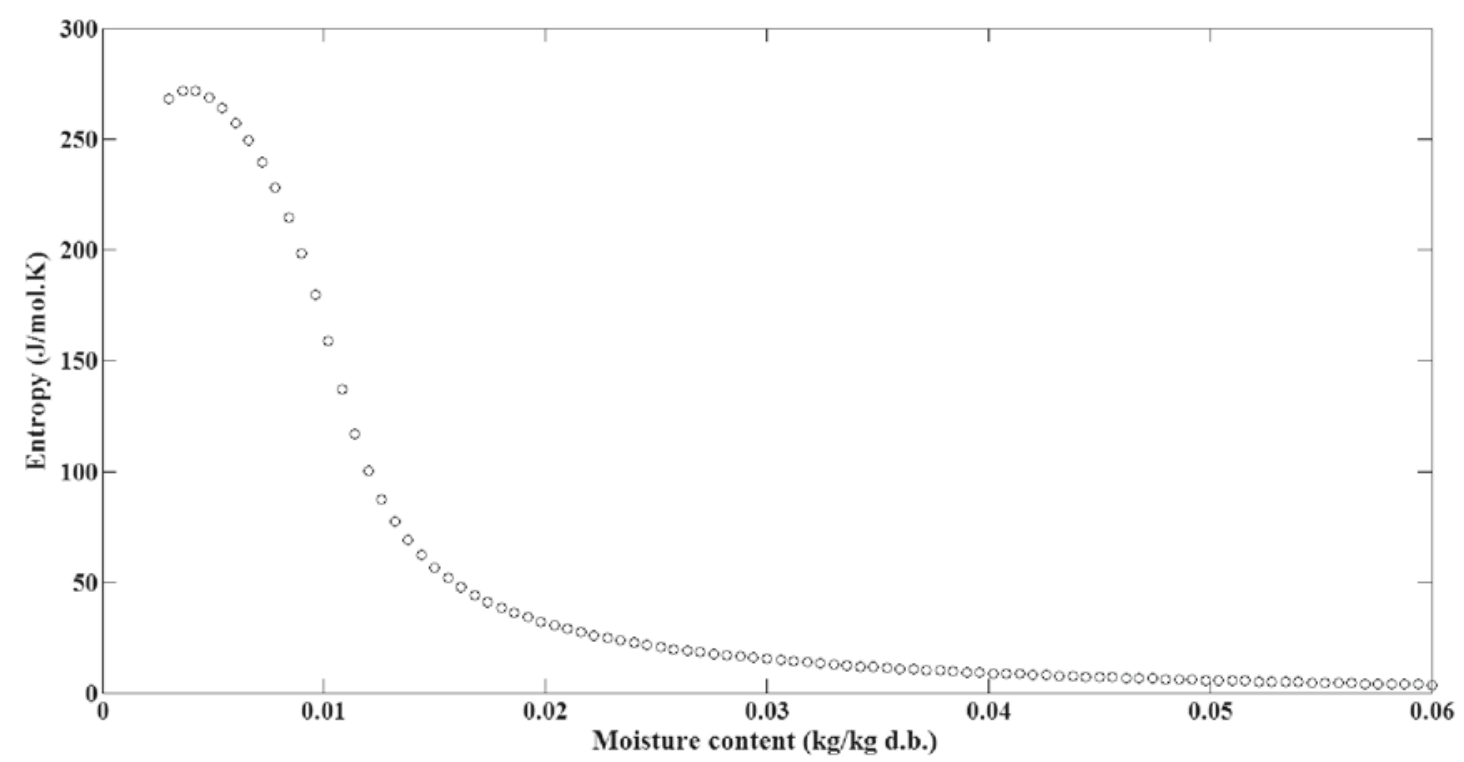

Figure 8. Variation of desorption entropy with moisture content of kaolin

ence of desorption entropy on moisture content with an exponential trend similar to that of desorption enthalpy.

\section{Density and shrinkage}

Figure 9 shows the evolution of the density of kaolin as a function of moisture content.

It is interesting to note that the density increases at the beginning of drying, reaches a maximum at a moisture

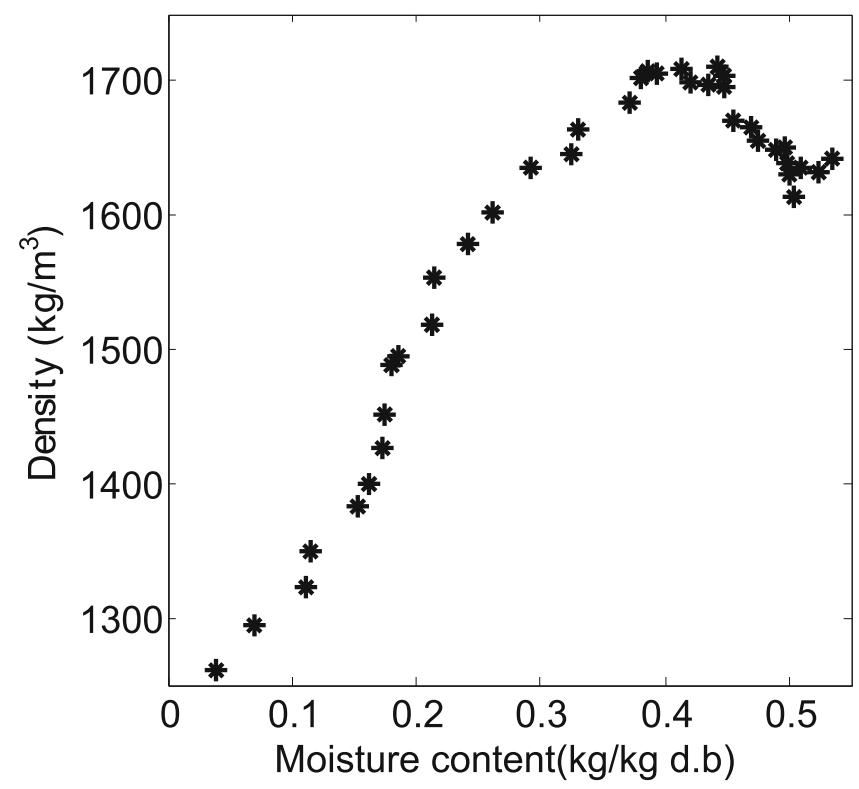

Figure 9. Variation of the density of kaolin as function of moisture content

content of $0.4 \mathrm{~kg} / \mathrm{kg}$ d.b and then decreases. This evolution is the result of superposition of two phenomena: mass reduction and volume reduction. At the beginning of drying, water migration causes a narrowing of the elements of the solid matrix which causes a decrease in the volume and an increase in density. The mass and the volume of the sample decrease but the effect on volume prevails. Then, when the effect of weight reduction dominates, a decrease of the density is observed. For low water content, the movement of elements of the matrix becomes more difficult, and the volume shrinkage stops, therefore, only the effect of the weight decrease dominates a decrease in the density. These results are consistent with other works ${ }^{5,18,22}$.

\section{Specific volume and shrinkage}

The variation of the specific volume can be determined from the evolution of the density. Figure 10 shows that the variation specific volume of kaolin as a function of water content follows an additive law for values of moisture content above 0.26. Above this value, the specific volume is written as:

$$
\begin{aligned}
& \bar{V}=\bar{V}_{\mathrm{s}}+\overline{\mathrm{V}}_{\mathrm{e}}\left(\mathrm{w}-\mathrm{w}_{\mathrm{r}}\right)=10^{-3}\left(0.7268+0.751\left(\mathrm{w}-\mathrm{w}_{\mathrm{r}}\right)\right) \\
& \text { Then } \varepsilon=\frac{\overline{\mathrm{V}}_{\mathrm{e}}}{\overline{\bar{V}}_{\mathrm{s}}}=1.0332 \text { and }
\end{aligned}
$$

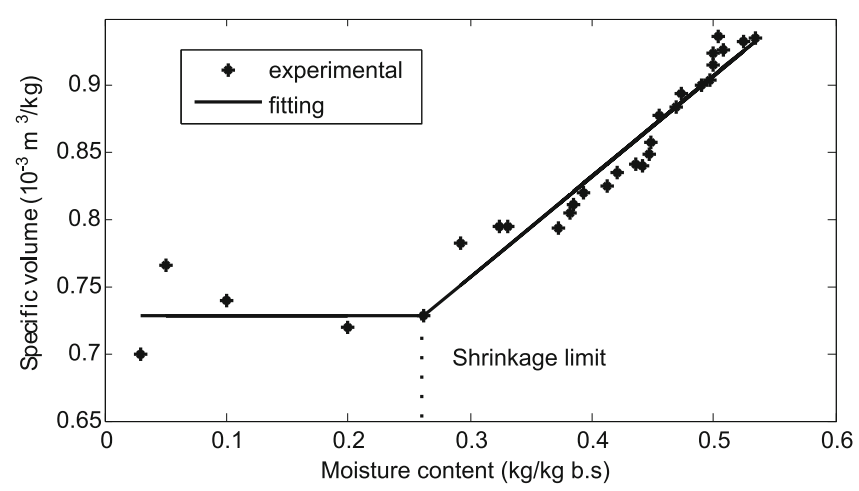

Figure 10. Variation of specific volume of kaolin as a function of moisture content

For $\mathrm{w} \leq 0.2617$

$\bar{V}=0.726810^{-3} \mathrm{~m}^{3} / \mathrm{kg}$. So $\rho_{\mathrm{s}}=1376 \mathrm{~kg} / \mathrm{m}^{3}$

Finally the following expressions describing density variation of kaolin are obtained:

If $\mathrm{w} \leq 0.2617$ then

$\rho=1376(1+w)$

If $w \geq 0.2617$ then

$\rho=1376 \frac{(1+w)}{(1+1.0332(w-0.26))}$ 


\section{Young's modulus determination}

During a compression test the kaolin sample exhibits an elastic linear stress-strain relationship up to a welldefined yield point. The linear portion of the curve is the elastic region and the slope is modulus of elasticity or Young's modulus (Fig. 11). Young's modulus and yield stress of kaolin depend on the moisture content.

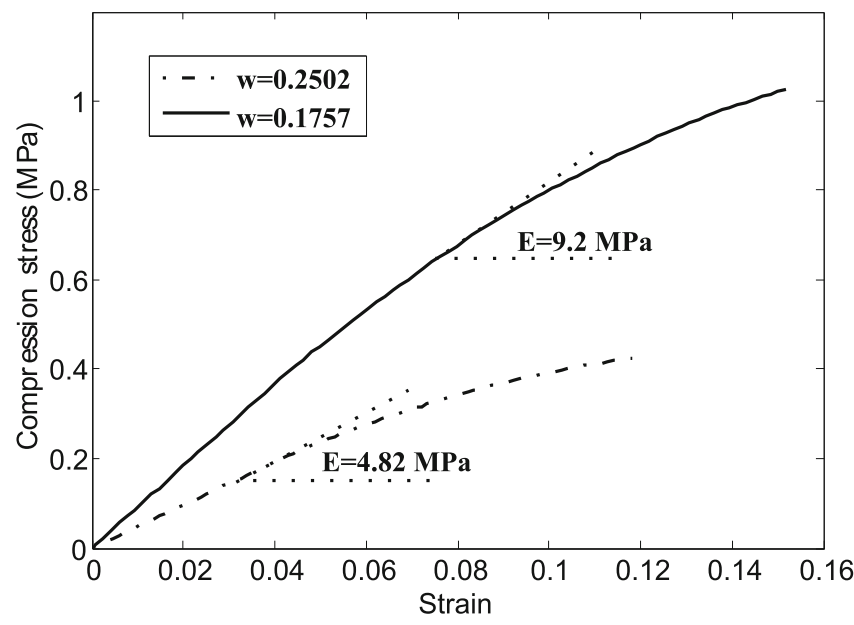

Figure 11. Uniaxial stress as function of strain applied to a kaolin sample

The variation of Young's modulus as a function of water content is presented in Figure 12. Young's modulus varies from $13 \mathrm{MPa}$ for $\mathrm{w}=0$ to $0.1 \mathrm{MPa}$ for $\mathrm{w}=0.4$ $\mathrm{kg} / \mathrm{kg}$ d.b. For low moisture contents, the variation of Young's modulus as a function of moisture content is negligible seen that for low moisture contents the solid skeleton imposes the behaviour of the product (non deformable). Whereas, for high moisture content, the variation of Young's modulus depends strongly on the moisture content because the material become deformable. Therefore, the moisture content plays an important role in the behaviour of the product. These results were observed confirmed by other authors for similar clays ${ }^{\mathbf{5}}$.

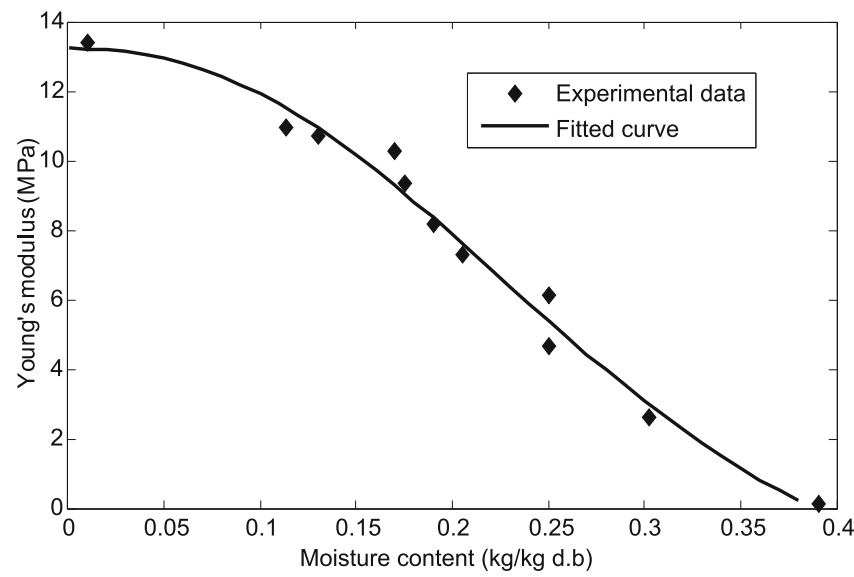

Figure 12. Variation of Young's modulus with moisture content of kaolin

\section{Relaxation function}

The experimental variation of the relaxation modulus versus time was presented in Figure 13.

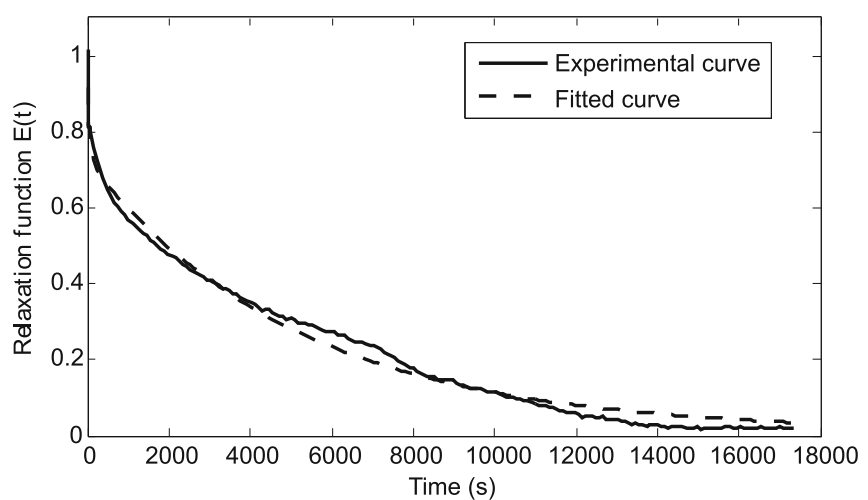

Figure 13. Relaxation function of kaolin versus time

In several researches concerning material rheology, the relaxation function $\mathrm{E}(\mathrm{t})$ of a viscoelastic material is represented by the following Prony series ${ }^{\mathbf{4 1}, 42}$

$\mathrm{E}(\mathrm{t})=\mathrm{E}_{\infty}+\sum_{\mathrm{i}=1}^{\mathrm{N}} \mathrm{E}_{\mathrm{i}} \mathrm{e}^{-\beta_{\mathrm{i}} \mathrm{t}}$

With $\mathrm{E}_{\infty}$ is the long term modulus once the material is totally relaxed,

where $E_{i}$ represents the stiffness of the spring in the ith Maxwell branch, and $\tau_{\mathrm{i}}$ is the relaxation time constant of the spring-dashpot pair in the same branch.

$\beta_{\mathrm{i}}=\frac{1}{\tau}$ is the reverse of the relaxation time constant of the spring-dashpot pair in the same branch.

The determination of $\mathrm{E}_{\infty}, \mathrm{E}_{1}, \ldots, \mathrm{E}_{\mathrm{N}, \ldots} \beta_{1 .} \beta_{\mathrm{N}}$ were made by using a non-linear least squares procedure. For various moisture contents, all the characterizations show that three Maxwell modules are sufficient to describe the clay viscoelastic behaviour. Hence, three elastic modules and two characteristic times are evaluated from fitting relaxation curves (Fig. 13 and Table 3).

$\mathrm{E}(\mathrm{t})=0,02+0,22 \mathrm{e}^{-0,027 \mathrm{t}}+0,71 \mathrm{e}^{-0,0002 \mathrm{t}}$

The kaolin can be fitted with Maxwell model with three branches as shown in Figure 13

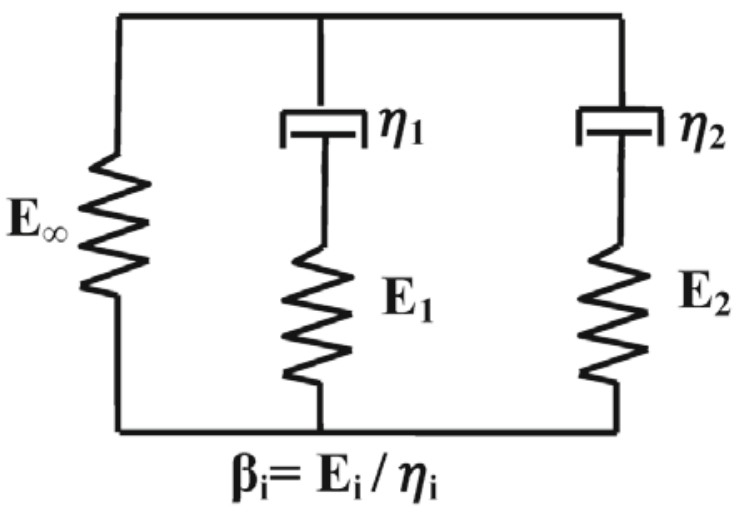

Figure 14. Schematic illustration of the Maxwell model of kaolin

Two elastic modules are predominant: instantaneous elastic modulus E1 and modulus E2 associated with the characteristic times 37 and 5000 s. Those characteristic times are short compared to the total drying time so stress relaxation can occur.

Table 3. The results of fitting of the experimental relaxation function of kaolin with a series of Prony

\begin{tabular}{|l|c|c|c|c|c|c|c|}
\hline $\mathrm{N}$ & $\mathrm{E}_{\infty}(\mathrm{MPa})$ & $\mathrm{E}_{1}(\mathrm{MPa})$ & $\mathrm{E}_{2}(\mathrm{MPa})$ & $\beta_{1}\left(\mathrm{~s}^{-1}\right)$ & $\beta_{2}\left(\mathrm{~s}^{-1}\right)$ & $\mathrm{S}$ & $\mathrm{R}^{2}$ \\
\hline 2 & 0.02 & 0.22 & 0.71 & 0.027 & 0.0002 & 0.02 & 99.68 \\
\hline
\end{tabular}




\section{CONCLUSION}

This work presents the variations of thermo-physical and rheological properties of kaolin as a function of moisture content. The desorption isotherms of kaolin were determined for three temperatures (30, 50 and $70^{\circ} \mathrm{C}$ ). The modelling of the desorption isotherms by $\mathrm{GAB}$ equation shows that this model is able to reproduce the evolution of equilibrium moisture content with the water activity for the moisture range varying from 0 to $0.06 \mathrm{~kg} / \mathrm{kg}$ d.b. $\left(0.9321 \leq \mathrm{R}^{2} \leq .0 .9506\right.$ and $2.9 .10^{-2} \leq \mathrm{S} \leq$ $\left..5 \cdot 3 \cdot 10^{-2}\right)$. The isosteric enthalpy and sorption entropy were also determined and show a decrease with moisture content. Density and shrinkage were determined in order to foresee the variation of kaolin volume. Mechanical characteristics such as Young's modulus and relaxation function of kaolin were identified. The results show that the kaolin Young's modulus varies considerably with moisture content, especially for high values of moisture content. Relaxation test allows the determination of viscoelastic parameters of kaolin and consequently to describe more the real mechanical behaviour of the product.

\section{LITERATURE CITED}

1. Bilali, L., Kouhila, M., Benchanaa, M., Mokhlisse, A. \& Belghith, A. (2001). Experimental study and modelling of isotherms of sorption of humid natural phosphate. Energy Convers. Manage. 42(4), 467-481. DOI: 10.1016/s0196-8904(00)00071-6.

2. Jomaa, W. \& Puiggali, J.R. (1991). Drying of shrinkage materials: modelling with shrinkage velocity. Drying Technol. 9(5), 1271-1293. DOI: 10.1080/07373939108916750.

3. Mihoubi, D. \& Bellagi, A. (2009). Stress Generated During Drying of Saturated Porous Media. Transp. Por. Med. 80(3), 519-536. DOI: 10.1007/s11242-009-9378-1.

4. Kowalski, S.J. \& Rybicki, A. (1996). Drying Stress Formation Induced by Inhomogeneous Moisture and Temperature Distribution. Transp. Por. Med. 24(2), 139-156. DOI: 10.1007/ bf00139842.

5. Ketelaars, A.A. J. (1993). Drying deformable media, kinetics, shrinkage and stress. University of Endhoven.

6. Zhang, Wshan \& Mujumdar, A.S. (1992). Deformation and stress analysis of porous capillary bodies during intermittent volumetric thermal drying. Drying Technol. 10(2), 421-443. DOI: $10.1080 / 07373939208916444$.

7. Akiyama, T., Liu, H. \& Hayakawa, K.I. (1997). Hygrostress multi-crack formation and propagation in cylindrical viscoelastic food undergoing heat and moisture transfer processes. Int $J$. Heat Mass Transfer. 40(7), 1601-1609. DOI: 10.1016/s00179310(96)00206-2.

8. Jia, C.C., Yang, W., Siebenmorgen, T.J. \&Cnossen, A.G. (2002). Development of computer simulation software for single grain kernel drying, tempering, and stress analysis. Transactions of the Asae 45(5), 1485-1492.

9. Mihoubi, D., Zagrouba, F., Vaxelaire, J., Bellagi, A. \& Roques, M. (2004). Transfer phenomena during the drying of a shrinkable product: modelling and simulations. Drying Technol. 22(1-2), 91-109. DOI: 10.1081/drt-120028216.

10. Hammouda, I. \& Mihoubi, D (2013). Modelling of drying induced stress of clay: elastic and viscoelastic behaviours. Mechanics of Time-Dependent Materials. 1-15. DOI: 10.1007/ s11043-013-9216-2.

11. Mihoubi, D. \& Bellagi, A. (2012). Modeling of heat and moisture transfers with stress-strain formation during convective air drying of deformable media. Heat and Mass Transfer. 48(10), 1697-1705. DOI: 10.1007/s00231-012-1014-x.
12. Kowalski, S.J., Musielak, G., Rybicki, A. \& Sliwa, T. (2012). Stresses and Strains in Elastic, Viscoelastic, and Plastic Materials during Drying. Drying Technol. 30(11-12), 1176-1189. 10.1080/07373937.2012.692745

13. Brasiello, A., Adiletta, G., Russo, P., Crescitelli, S., Albanese, D. \& Di Matteo, M. (2013). Mathematical modeling of eggplant drying: Shrinkage effect. J. Food Eng. 114 (1), 99-105. DOI: 10.1016/j.jfoodeng.2012.07.031.

14. Dhall, Ashish \& Datta, Ashim, K. (2011). Transport in deformable food materials: A poromechanics approach. Chem. Eng. Sci. 66(24), 6482-6497. DOI: 10.1016/j.ces.2011.09.001.

15. Wolf, W., Spiess, W.E.L. \& Jung, G. (1985). Standardization of isotherm measurements (COST-Project 90 and 90 bis). In D. Simatos and J.L. Multon (Eds.), Properties of Water in Foods, vol. 90, 661-679, Springer Netherlands.

16. Ruegg, M. (1980). Calculation of the activity of water in sulphuric acid solutions at various temperatures. Lebensmittel-Wissenschaft und Technologie. 13(22-24).

17. Kechaou, N. (1989). Séchage des gels fortement déformables: études de la diffusion interne de l'eau et modélisation. Institut National Polytechnique de Loraine, Loraine.

18. Mihoubi, D., Zagrouba, F., Ben Amor, M. \& Bellagi, A. (2002). Drying of clay: I. Material Characteristics. Drying Technol. 20(2), 465-487. DOI: 10.1081/drt-120002552.

19. Timoumi, S., Mihoubi, D. \& Zagrouba, F. (2007). Shrinkage, vitamin $\mathrm{C}$ degradation and aroma losses during infra-red drying of apple slices. Lwt-Food Science and Technology. 40(9), 1648-1654. DOI: 10.1016/j.lwt.2006.11.008.

20. Mihoubi, D. \& Bellagi, A. (2006). Thermodynamic analysis of sorption isotherms of bentonite. J Chem Thermodyn. 38(9), 1105-1110. DOI: 10.1016/j.jct.2005.11.010.

21. Chemkhi, S., Zagrouba, F. \& Bellagi, A. (2004). Thermodynamics of water sorption in clay. Desalination. 166(1-3), 393-399. DOI: 10.1016/j.desal.2004.06.094.

22. Collard, J.M. (1989). Etude des transferts d'humidité et des déformations pendant le séchage d'une plaque d'argile. thèse de doctorat, Thèse de l'université de Poitiers,

23. Langmuir, Irving (1918). The adsorption of gases on plane surfaces of glasses, mica et platinum. J. Am. Chem. Soc. 40(9), 1361-1403. DOI: 10.1021/ja02242a004.

24. Brunauer, S., Deming, L.S., Deming, W.E. \& Troller, E. (1940). On the theory of Van der Waals adsorption of gases. J. of Amer. Chem. Soc. 62, 1723-1732.

25. Bradley, R.S. (1936). Polymer adsorbed films. Part I. The adsorption of argon on salt crystals at low temperatures and the determination of surface fields. J. of Chem. Soc. 58, 1467-1474.

26. Kühn, I. (1964). A new theoretical analysis of adsorption phenomena. Introductory part: The characteristic expression of the main regular types of adsorption isotherms by a single simple equation. J. of Coll. Sci. 19(8), 685-698. http://dx.doi. org/10.1016/0095-8522(64)90076-5

27. Zsigmondy, R. (1911). Über die struktur des gels der kieselsaure, Theorie der entwasserung. Zeitschrift für anorganische Chemie. 71(1), 356-377. DOI: 10.1002/zaac.19110710133.

28. Henderson, S.M. (1952). A basic concept of equilibrium moisture. Agriculture Engineering. 33(1), 23-32.

29. Iglesias, H.A. \& Chirife, J. (1976). Prediction of the effect of temperature on water sorption isotherms of food material. Int. J. Food Sci. Technol. 11(2), 109-116. DOI: 10.1111/j.13652621.1976.tb00707.x.

30. Lykov, A.V. (1955). Experimentelle und theoretische grundlagen der trocknung V. E. B. Verlag.

31. Iglesias, H. A. \& Chirife, J. (1978). An empirical equation for fitting water sorption isotherms of fruits and related products. Canadian Institute of Food Science and Technology Journal. 11(1), 12-15. http://dx.doi.org/10.1016/S0315-5463(78)73153-6

32. Roques, M. (1988). Equilibre entre un solvant et un solide, stage de perfectionnement de séchage. Centre de Perfectionnement des Industries Chimiques de Nancy. 
33. Anderson, Robert B. (1946). Modifications of the Brunauer, Emmett and Teller Equation1.J. Am. Chem. Soc. 68(4), 686-691. DOI: 10.1021/ja01208a049.

34. Brunauer, S., Emmett, P.H. \& Teller, E. (1938). Adsorption of Gases in Multimolecular Layers. J. Am. Chem. Soc. 60(2), 309-319. DOI: 10.1021/ja01269a023.

35. Thompson, T.L., Peart, R.M. \& Foster, G.H. (1986). Mathematical simulation of corn drying: a new model. Transactions of the American Society of Agricultural Engineers 11(4), 0582-0586. DOI: 10.13031/2013.39473.

36. Chirife, J. \& Iglesias, H.A. (1978). Equations for fitting water sorption isotherms of foods: Part 1 - a review. Int. J. Food Sci. Technol. 13(3), 159-174. DOI: 10.1111/j.13652621.1978.tb00792.x

37. Peleg, M. (1993). Assessment of a semi-empirical four parameter general model for sigmoid moisture sorption isotherms. Journal of Food Process Engineering. 16(1), 21-37. DOI: 10.1111/j.1745-4530.1993.tb00160.x.

38. Rizvi, S.S.H. (2005). Thermodynamics of food and dehydration. In Engineering Properties of Foods, Third Edition: CRC Press.

39. Arslan, N. \& Toğrul, H. (2005). Moisture Sorption Isotherms for Crushed Chillies. Biosyst. Eng. 90(1), 47-61. http:// dx.doi.org/10.1016/j.biosystemseng.2004.10.008

40. McMinn, W.A.M., Al-Muhtaseb, A.H. \& Magee, T.R.A. (2005). Enthalpy-entropy compensation in sorption phenomena of starch materials. Food Res. Int. 38(5), 505-510. http://dx.doi. org/10.1016/j.foodres.2004.11.004

41. Pourcel, F., Jomaa, W., Puiggali, J.R. \&Rouleau, L. (2007). Crack Appearance during Drying of an Alumina Gel: Thermo-Hydro-Mechanical Properties. Drying Technol. 25(4-6), 759-766. DOI: 10.1080/07373930701370134.

42. Takhar, Pawan, S. (2011). Hybrid Mixture Theory Based Moisture Transport and Stress Development in Corn Kernels During Drying: Coupled Fluid Transport and Stress Equations. J. Food Eng. 105(4), 663-670. http://dx.doi.org/10.1016/j.jfoodeng.2011.03.033 